\title{
Voltage Management in Unbalanced Low Voltage Networks Using a Decoupled Phase- Tap-Changer Transformer
}

\author{
Coppo, Massimiliano ; Turri, Roberto ; Marinelli, Mattia; Han, Xue
}

Published in:

Proceedings of International Universities' Power Engineering Conference (UPEC) 2014

Link to article, DOI:

10.1109/UPEC.2014.6934809

Publication date:

2014

Link back to DTU Orbit

Citation (APA):

Coppo, M., Turri, R., Marinelli, M., \& Han, X. (2014). Voltage Management in Unbalanced Low Voltage Networks Using a Decoupled Phase-Tap-Changer Transformer. In Proceedings of International Universities' Power Engineering Conference (UPEC) 2014 [6934809] IEEE. https://doi.org/10.1109/UPEC.2014.6934809

\section{General rights}

Copyright and moral rights for the publications made accessible in the public portal are retained by the authors and/or other copyright owners and it is a condition of accessing publications that users recognise and abide by the legal requirements associated with these rights.

- Users may download and print one copy of any publication from the public portal for the purpose of private study or research.

- You may not further distribute the material or use it for any profit-making activity or commercial gain

- You may freely distribute the URL identifying the publication in the public portal 


\section{Voltage Management in Unbalanced Low Voltage Networks Using a Decoupled Phase-Tap-Changer Transformer}

\author{
Massimiliano Coppo, Roberto Turri \\ Department of Industrial Engineering \\ University of Padova, Italy
}

\author{
Mattia Marinelli, Xue Han \\ Department of Electrical Engineering (CEE) \\ DTU- Technical University of Denmark
}

\begin{abstract}
The paper studies a medium voltage-low voltage transformer with a decoupled on load tap changer capability on each phase. The overall objective is the evaluation of the potential benefits on a low voltage network of such possibility. A realistic Danish low voltage network is used for the analysis. The load profiles are characterized by using single phase measurement data on voltages, currents and active powers with a 10 minutes resolution. Different scenarios are considered: no tap action, three-phase coordinated tap action, single phase discrete step and single phase continuous tap action. The effectiveness of the tapping capability is evaluated by comparing the Voltage Unbalance Factor and the voltage levels on the neutral cable.
\end{abstract}

Index Terms-Distributed Generation, Automatic Voltage Control, Power Transformer, Smart Grids

\section{INTRODUCTION}

Many recent projects envisaged the possibility to modulate the energy consumption in LV networks by modulating the feeding voltage of the end-users [1], [2]. This approach, known as CVR (Conservation Voltage Reduction), is suitable for networks with three-phase users, therefore with balanced voltage on the three phases.

However, the increasing presence of Distributed Energy Resources (DERs) like photovoltaic and new storage-capable loads (e.g., plug-in hybrid electric vehicles), may result into non-monotonic voltage variations along the feeder, which may actually be mitigated by proper management of reactive power provision of small photovoltaic generators [3] or electric vehicles [4].

The effects of different control strategies for three-phase inverter-connected DG-units on voltage unbalance in distribution networks have been presented in [5] to study both the voltage negative-and zero sequence components.

Furthermore, since LV networks host both single and three-phase users, the different power flow on the phases may result into some voltage unbalance issues that can interfere with voltage control strategy (i.e. CVR).
The problem of network regulation in unbalanced conditions is addressed in [6], [7] and [8] where different control strategies of embedded three and four wire inverters are presented.

A solution for the voltage conditioning in LV networks is presented considering an on-load-tap-changing (OLTC) operation of the secondary substation transformer. Some commercial products are already available for the scope relying on electronic switching capability [9] and are commonly known as smart transformers [10].

The novelty of the proposed approach is the management of voltage unbalances decoupling the tap variation among the phases. It means that in case one of the phase voltages is particularly loaded, the transformer will reduce the ratio just on that specific phase, without involving configuration changes of the other two phases.

The methodology adopted in this study is described in Section II along with the modelling approach used for the OLTC phase-wise transformer. Several scenarios are defined in Section III along with the relevant information of a real LV Danish network. The results are presented in Section IV and the final remarks and future studies are reported in Section V.

\section{Methodology}

\section{A. Problem statement}

It is common in Denmark to have three phases connection available even for relatively small residential users and, depending on the layout of the household electrical installation, concurrent loads may be concentrated on just one phase. Moreover, the increasing presence of small single phase distributed energy resources (DER) like photovoltaic and new storage-capable loads (e.g., plug-in hybrid electric vehicles), is leading into uncorrelated voltage variations along the feeder: it may happen that one phase voltage is increasing along the feeder, while the others are decreasing. Therefore, since LV networks host both single and threephase prosumers, the different power flow on the phases may 
lead to voltage unbalances that can interfere with the CVR control strategy.

The novelty of the proposed approach is the utilization of a decoupled OLTC MV/LV transformer, which is capable of regulating each single phase tap changer in a different way. A research project aimed at the realization of this kind of transformer is recently started and will foresee the testing on the experimental facility SYSLAB of the Ris $\varnothing$ DTU and a future application on the field.

The present work aims at providing, by evaluating achievements in term of voltage unbalances and losses reduction on a LV feeder, a feasibility analysis of an OLTC distribution transformer with decoupled tap capability. The tap changers can regulate the single phase voltage $\pm 5 \%$ the nominal value.

\section{B. Multi-Phase system modeling}

In order to perform the analysis in a LV distribution network, a power flow tool able to deal with asymmetrical systems is needed. The method adopted for this work has been classified as a Current Injection method and allows carrying out power flow analysis on multi-phase systems [12]. The principle leading to the composition of the potentially asymmetrical system is depicted in Fig. 1 where the Network Admittance Matrix is composed starting from the branches definition (self and mutual admittances) including lines and transformers. The system is then integrated with the shunt elements (whether they are loads or generators) which are represented as a parallel of constant admittances and variable current injectors, so the total current contribution depends on both terms and gives the possibility to change the models' voltage dependency.

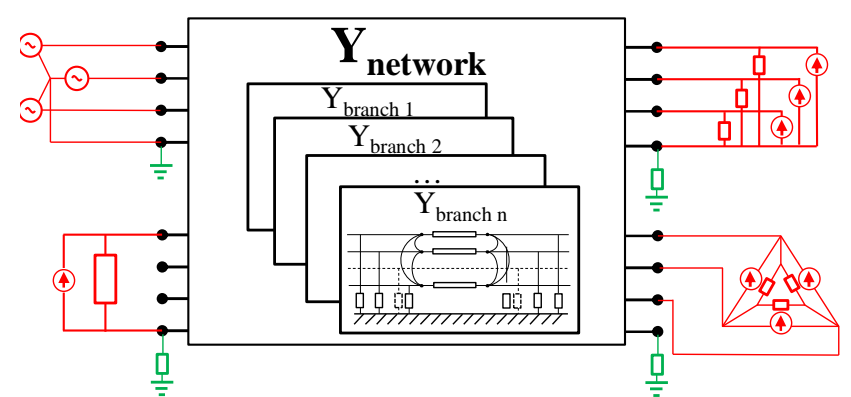

Fig. 1. System representation for the asymmetrical power flow analysis Shunt elements are connected to the external ports (red). Earth connection admittances may also be considered as external elements (green).

A similar approach is also adopted in the software OpenDSS released by EPRI [13] used in this work to compute the simulations presented in section IV.

\section{Transformer modeling}

Once the network model is built as for the scheme depicted in Fig. 2, the transformer needs to be represented as an admittance matrix connecting the PCC (LV busbar) to the MV network.
The classical approach used defining the transmission matrix of a generic single-phase transformer [14] is implemented to consider each phase's primitive matrix. Since for this work a control on the single phases was needed in order to independently control the transformer ratios, the model is built by three single-phase transformers, each secondary side connected between an earthed neutral point and a different phase of the LV grid, whereas at the primary side (MV busbar) the connection is made between two phases, as for the Delta connection, resulting in a three-phase Delta-Wye transformer model, as shown in Fig. 2.

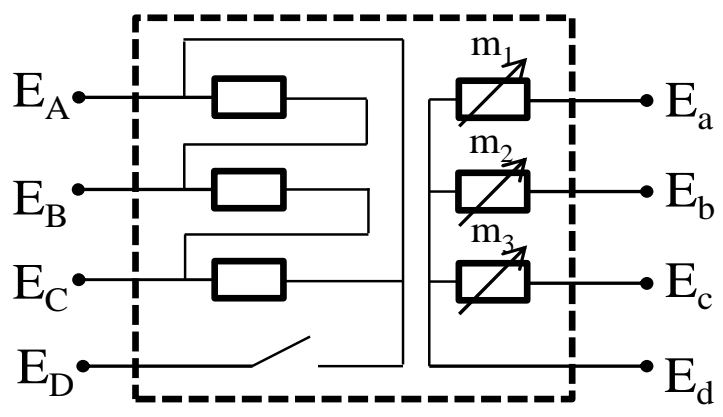

Fig. 2. Three phase Delta-wye transformer model.

Fig. 2 shows a schematic representation of the transformer model: in particular it can be noticed that, since the MV side works with isolated neutral, the fourth port is open, while at the secondary side the neutral point is connected to the relative conductor in the four-wire system. Furthermore, for this paper it has been considered that each phase of the LV side has the possibility to perform a tap-changing action, conditioning the relative phase voltage independently.

\section{NETWORK LAYOUT AND TESTING SCENARIOS}

\section{A. Danish low voltage network}

The network considered for application consists in a 12bus Danish LV feeder connected to the MV network through a 10/0.4 kV transformer as shown in Fig. 3 [15]. The short circuit power of the main network is 20 MVA.

Measurements on the real system allowed characterizing the power consumption of the 33 single phase loads during a 24-hours interval which resulted to be about $740 \mathrm{kWh}$, with a mean power of $30.8 \mathrm{~kW}$. The total energy and mean power amounts for each phase are reported in TableTABLE I.

The three-phase transformer is modeled as described in Section III enabling the phase-wise independent operation of the proposed OLTC.

TABLE I.

TOTAL LOAD ENERGY (24 HOURS) AND MEAN POWER VALUE.

\begin{tabular}{|l|r|r|r|}
\hline & Phase a & \multicolumn{1}{|c|}{ Phase b } & \multicolumn{1}{|c|}{ Phase c } \\
\hline Energy $[\mathrm{kWh}]$ & 295.5 & 201.2 & 242.4 \\
\hline Mean Power $[\mathrm{kW}]$ & 12.4 & 8.4 & 10.2 \\
\hline
\end{tabular}




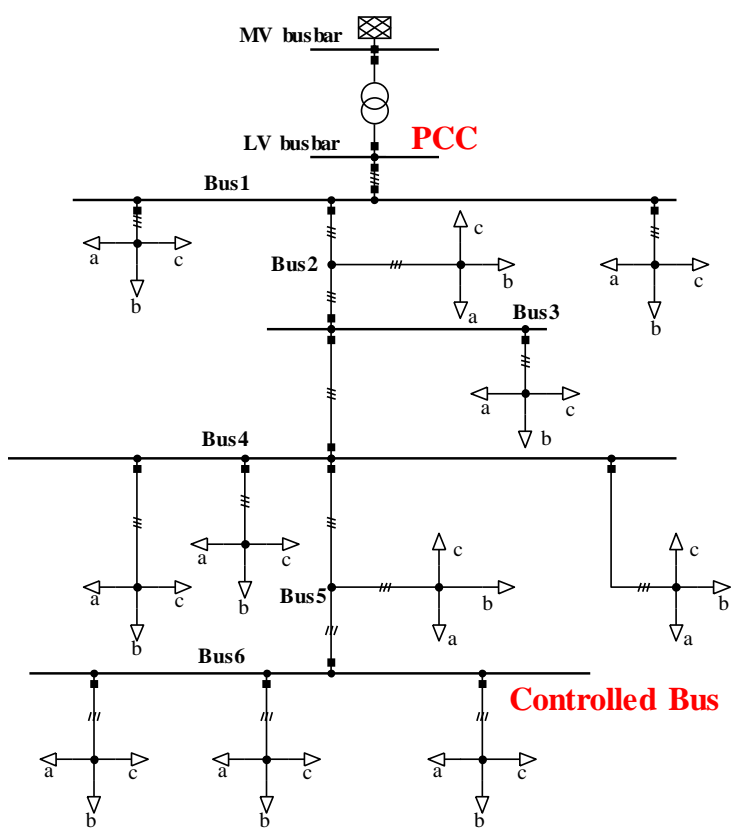

Fig. 3. Single line diagram of the Danish network.

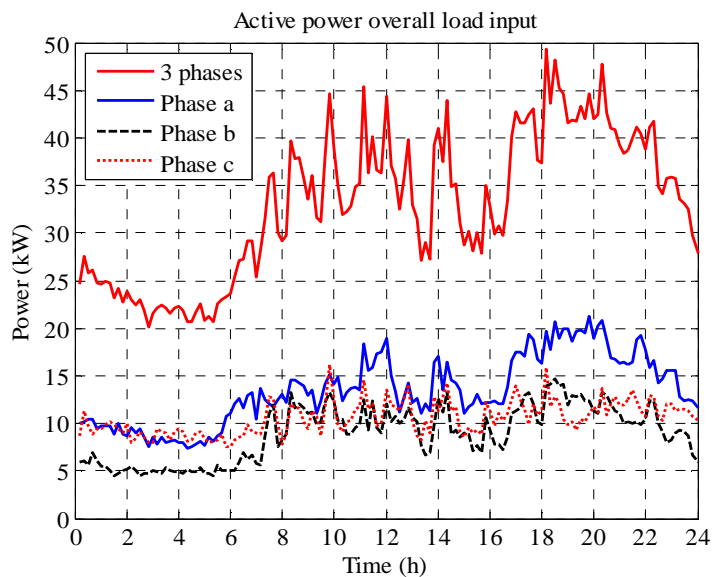

Fig. 4. Active power input on the three phases. Overall sum for the 33 single phase loads.

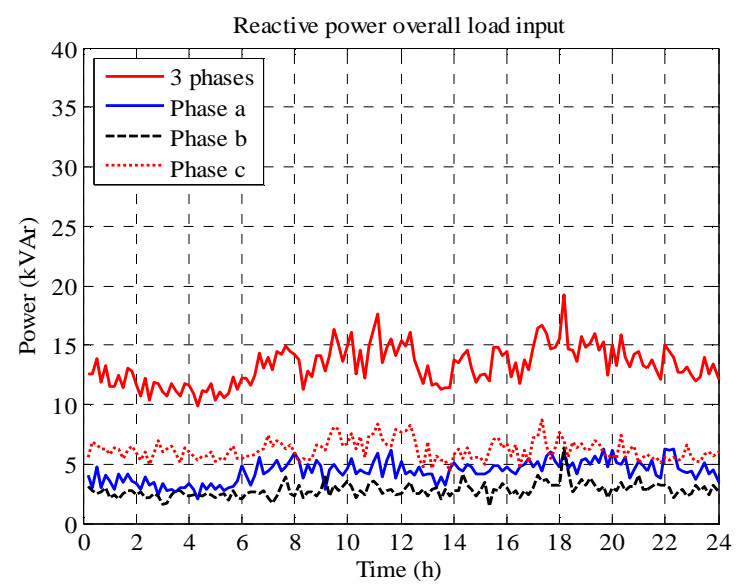

Fig. 5. Reactive power input on the three phases. Overall sum for the 33 single phase loads.

\section{B. Simulation scenarios}

The defined scenarios aim at investigating the effects of the OLTC installed at the MV/LV Substation. In particular, an analysis of the feeder-end phase voltages is made in order to evaluate the voltage magnitude and voltage unbalance level under different operating conditions.

Starting from the Base Case Scenario, derived from the voltage and currents measurements on the real system, three other scenarios are presented to evaluate the possible effects of the control:

1. Synchronized OLTC: the OLTC is operated simultaneously on the three phases, taking as reference the phase voltage at phase a. The tapchanging ratio is the same adopted for off-load operation in distribution transformers;

2. Phase-wise OLTC - discrete: three independent controllers are set referring each one to one phase of the system. The control uses the same tap changing ratio used for the synchronized action;

3. Phase-wise OLTC - continuous: the independent action of each phase is considered with a higher number of taps with smaller variations.

The OLTC controllers operate at the MV/LV transformer secondary busbar, using as input variable the voltage at the controlled bus (Bus 6 in Fig. 3) in each phase with the objective to minimize the voltage deviation with respect to a reference voltage $V_{\text {ref }}$, here set to 1 pu. The control considers a non-action zone around the mentioned reference voltage (called Dead-Band), in this work set at $\pm 2 \% V_{\text {ref }}$, with the possibility to switch on 5 positions for a total $\pm 5 \% \mathrm{Vn}$ variation, i.e. with steps of $\Delta V=2.5 \% \mathrm{Vn}$.

A more accurate regulation can be achieved with a finer control of the OLTC, maintaining the voltage variation range at $\pm 5 \% \mathrm{Vn}$ while reducing the step voltage variation $\Delta \mathrm{V}$ at $0.1 \% V n$ with a Dead-Band set at $\pm 0.25 \% V n$.

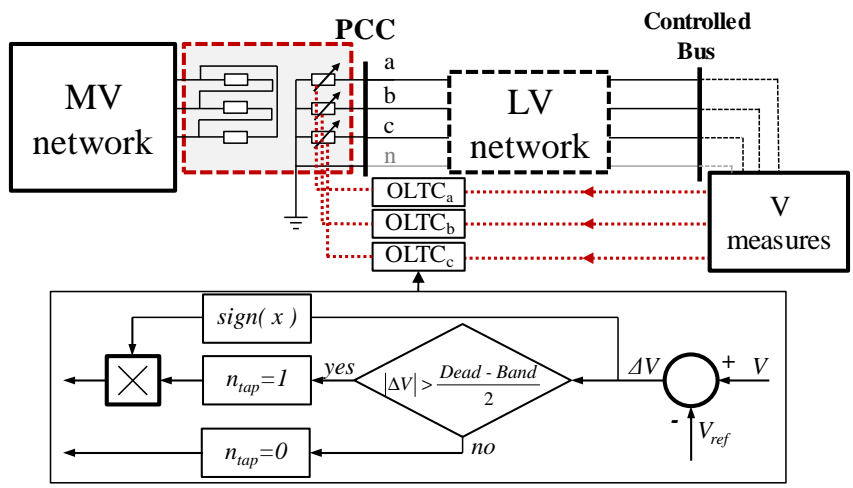

Fig. 6. Setup of the proposed control strategy. The OLTC control is shown in detail for one phase. The Dead-Band here is intended as the total range (i.e. $4 \%$ in scenarios $\mathrm{A}$ and $\mathrm{B}, 0.5 \%$ in scenario $\mathrm{C}$ ). 


\section{Simulation Results}

\section{Base Case Scenario - no OLTC}

The phase-neutral voltage profile over the 24 hour time period considered as a Base Case for simulations is shown in Fig. 7. As it can be seen, the profile follows what is expected in a residential area, with low loading during the night (from 0 to 6 a.m.) and higher absorption by loads in the evening (from 6 to 12 p.m.). The maximum voltage sag could be observed around 8 p.m. in phase a, with $0.955 \mathrm{pu}$.

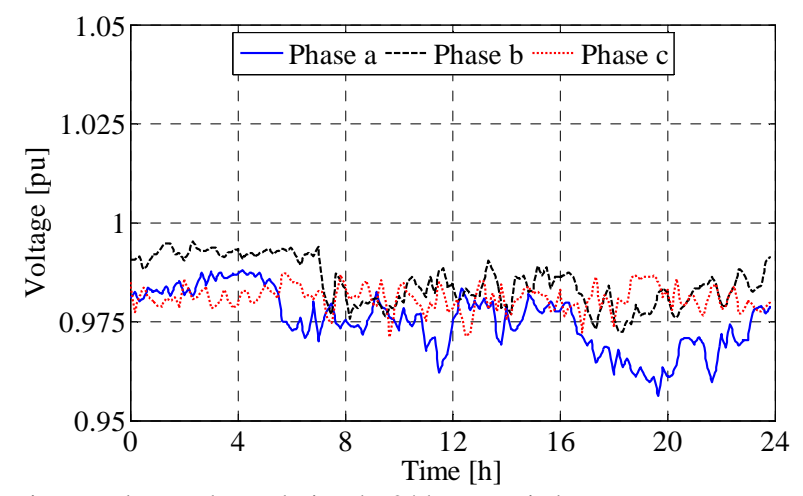

Fig. 7. Voltage at bus 6 during the 24 hours period

\section{Scenario A: Synchronous OLTC}

The first scenario considers the synchronous operation of the tap-changer controllers on the three phases. The hypothesis is that the OLTC uses as input variable the voltage measurement on one of the phases (in this case phase a). Fig. 8 shows the voltage profile on the controlled bus with the synchronous tap-change operation at the MV/LV transformer. It can be seen that the controller causes a $\Delta V=0.025 \mathrm{pu}$ variation $(\operatorname{tap}+1)$ when the phase a voltage at bus 6 overcomes the lower threshold $0.98 \mathrm{pu}$. When the power consumption by loads increases, at around $8 \mathrm{p} . \mathrm{m}$., the tap controller switches to $+2(\Delta \mathrm{V}=0.05 \mathrm{pu})$ causing a voltage rise on the other phases too.

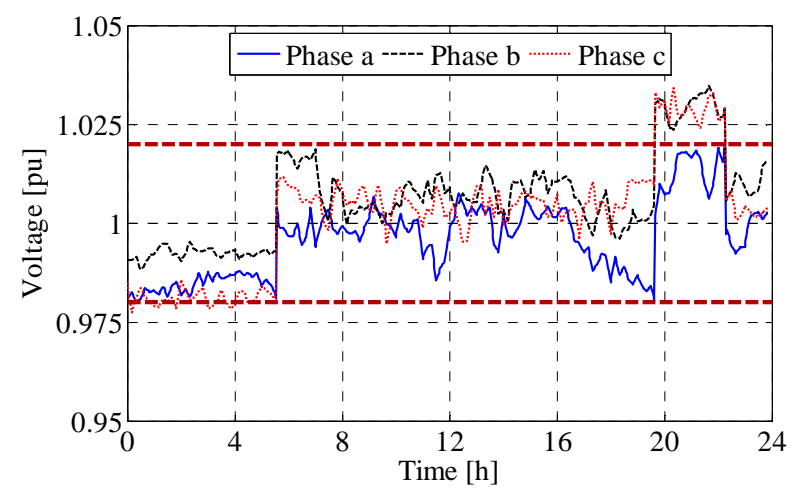

Fig. 8. Phase voltage at the controlled bus with synchronous tap change by MV/LV OLTC

\section{E. Scenario B: Phase-wise OLTC-discrete}

In the second scenario, the phase-wise operation by the OLTC is adopted. In this case the voltage measurements at the controlled bus are considered individually to perform the independent control on the three phases. For the sake of comparison, the steps ratio and total range for the OLTC are kept as for the previous scenario.

Fig. 9 shows the voltage profile during the 24 hours simulation at bus 6 with the phase-wise OLTC control. As it can be seen, the tap controllers react to the Dead-Band overcoming by the relative voltage in different instants reducing the deviations within the Dead-Band, but this operation could possibly adversely affect the voltage unbalance as shown in Fig. 10, where the Voltage Unbalance Factor (negative sequence) is evaluated in scenarios A and B as for the expression (1) [16]:

$$
V U F_{\%}=\frac{V_{\text {negative seq }}}{V_{\text {positive seq }}} \cdot 100
$$

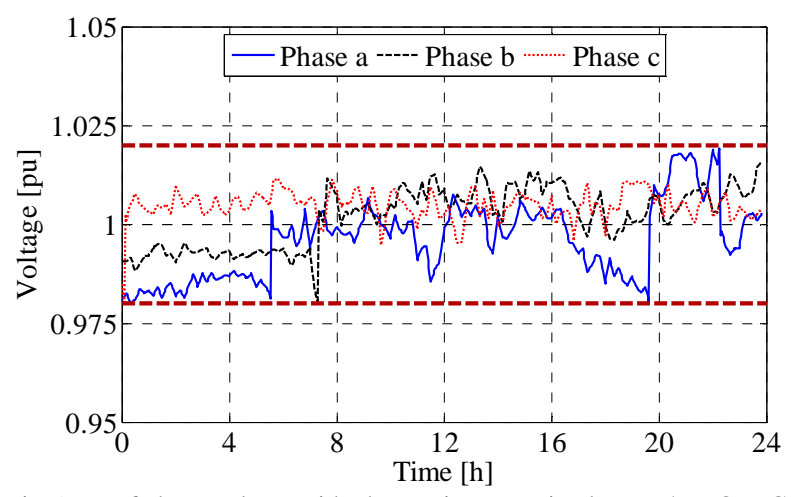

Fig. 9. Bus6 phase voltage with phase-wise operation by MV/LV OLTC.

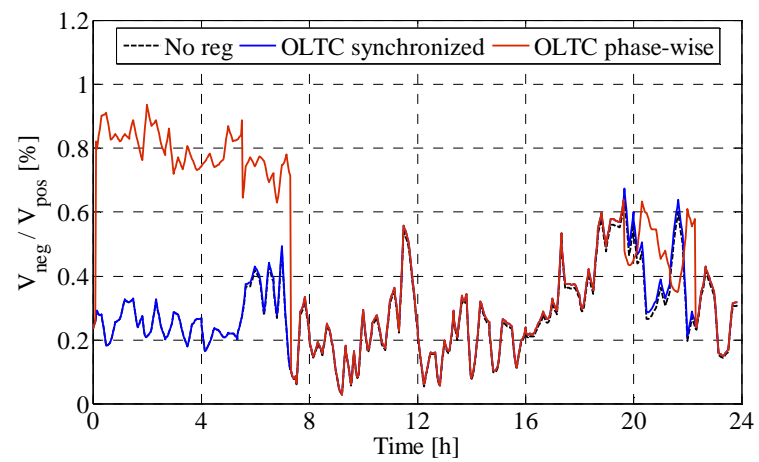

Fig. 10 Comparison between the unbalance in Synchronized and Phase-wise OLTC controls.

From the simulations it clearly emerges that, while a synchronous operation of the OLTC does not affect the unbalance level, the negative sequence content increases sensibly when the OLTC controller sets different positions on the phases. This effect is mainly given by the discreteness of 
the control, having taps which cause a voltage variation of 0.025 pu each.

\section{F. Scenario C: Phase-wise OLTC-continuous}

A significant improvement in the control could be given by a higher number of steps, pursuing a regulation as close to continuous as possible. In particular, the higher precision of the control enables to reduce the Dead-Band reaching a more accurate voltage regulation at Bus6 busbar. Fig. 11 shows the result in terms of phase voltages obtainable setting the DeadBand width at $0.5 \% \mathrm{Vn}$. In this case the control is more effective, containing the maximum deviations around $0.25 \%$ $V n$. In Fig. 12 a comparison between the unbalance in the discrete and continuous control is made, stressing the fact that a discrete control with less selective voltage variation may worsen the unbalance condition, while a continuous regulation may result not only in an overall voltage magnitude improvement, but also in smaller unbalances.

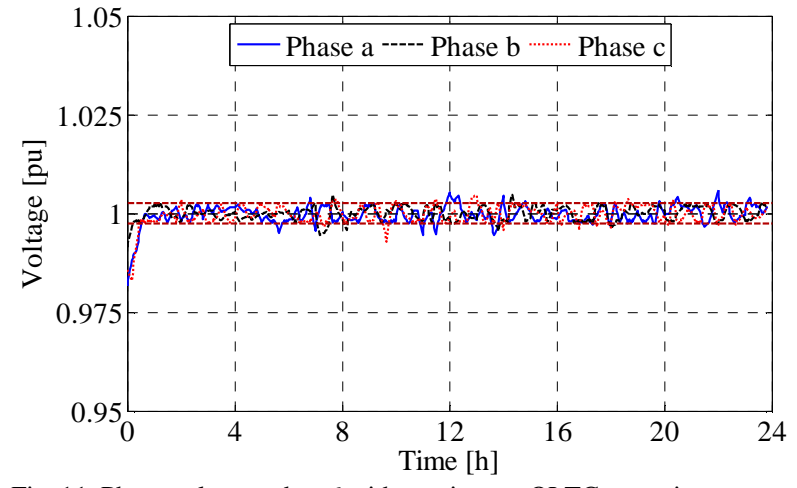

Fig. 11. Phase voltage at bus 6 with continuous OLTC operation.

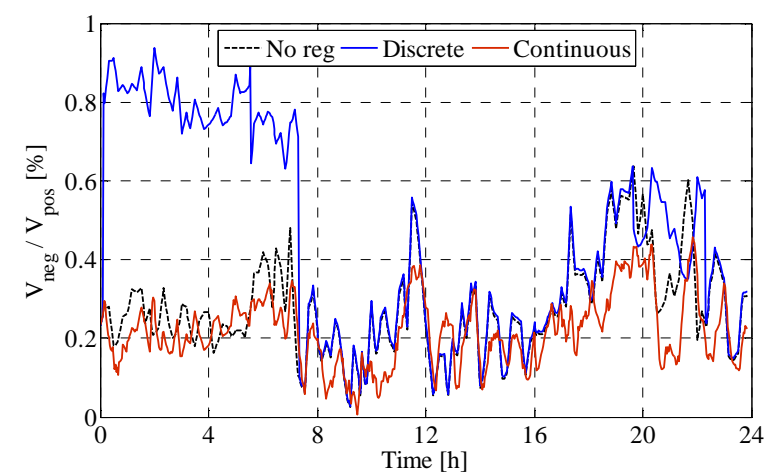

Fig. 12. Comparison of the VUF with the Discrete and Continuous OLTC control.

In Fig. 13 the voltage variation imposed by the OLTC on each phase in scenario $\mathrm{C}$ is shown. It clearly appears that the controller follows the voltage deviations at bus 6 operating to maintain the voltage within the assigned Dead-Band.

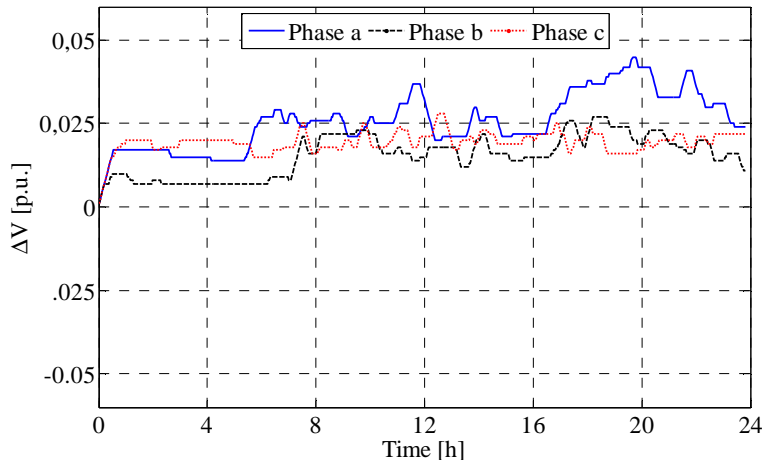

Fig. 13. Voltage variation by phase as for the Scenario C OLTC control.

In Table TABLE II the results discussed so far are summarized in terms of mean values.

TABLE II.

MEAN VALUES FOR THE VUF AND PHASE VOLTAGES IN THE SIMULATED SITUATIONS

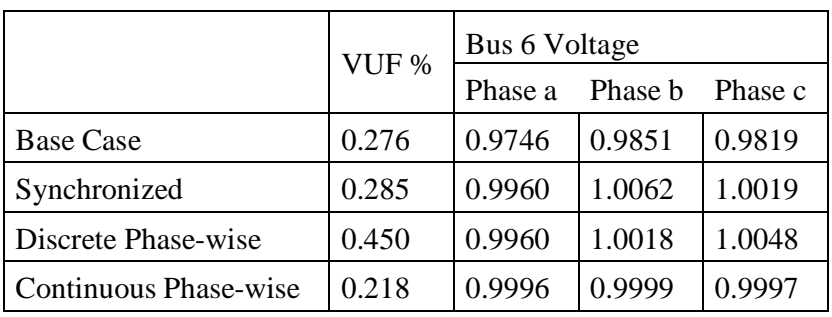

Finally in Fig. 14 the neutral potential at the controlled busbar is shown for each scenario. It could be seen that in all three situations the neutral potential is quite similar, just slightly higher in scenario $\mathrm{C}$. This tendency is justified by the fact that the voltage variation obtained does not induce a sensible variation on the phase currents; as a consequence the voltage drop on the neutral conductor remains nearly the same.

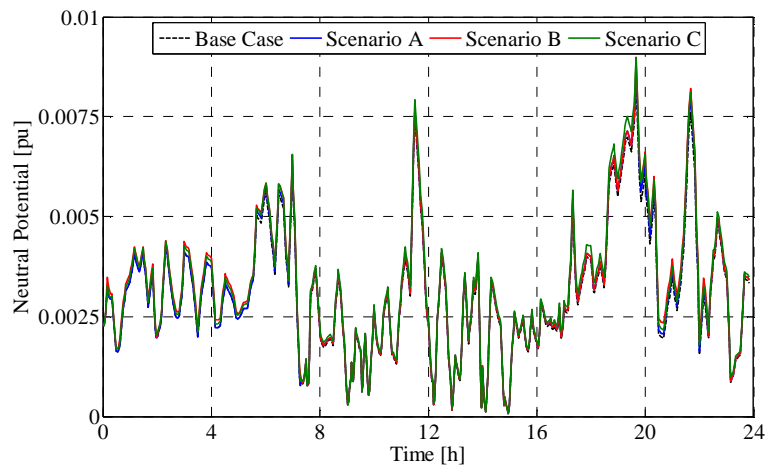

Fig. 14. Neutral potential at bus Bus6 under the different scenarios. 


\section{CONCLUSIONS AND FUTURE WORKS}

This paper focuses on the possibility to control the LV distribution networks voltage through an On Load Tap Changer at the Secondary Substation Transformer.

Data and measurements on a Danish LV feeder have been used in a 24-hour time simulations in order to assess the possible effects of this kind of control on a real system.

The three scenarios considered different features dealing with progressive levels of discretization on the voltage control. The results in terms of phase voltage magnitude and unbalance highlighted the fact that the phase-wise operation of the OLTC although providing a better control on the overall voltage deviations, may also result in an unbalance worsening when applying a discrete tap change with large steps. The continuous operation of the OLTC may instead result in a better control improving the voltage quality on both the magnitude and unbalance standpoints.

The results indicate that a phase-wise OLTC although reducing the voltage deviations does not sort any effect on the neutral conductor potential. Some improvements in that sense may come from an active management of the power exchange by the users.

The objective of future works is to extend the simulations analysis over a longer time period (weeks) and to analyse the influence of renewable sources, such as small three-phase and single-phase photovoltaic generators, on the on load tap changing strategy.

During 2015, the studied transformer will be tested in the experimental facility SYSLAB-PowerLab.DK of the DTU Risø Campus.

\section{AKNOWLEDGEMENTS}

This work has been partly funded by the Energy Saving by Voltage Management Project (EUDP - Danish project). The authors thank for the useful discussions the team of PSS Energy Group A/S and DONG Energy and thank Dr. Junjie $\mathrm{Hu}$ for the help in preparing the input data.

\section{REFERENCES}

[1] K.P. Schneider, F.K. Tuffner, J.C. Fuller and R. Singh, "Evaluation of Conservation Voltage Reduction (CVR) on a National Level," Pacific Northwest National Laboratory, July 2010
[2] S. Rahimi, M. Marinelli and F. Silvestro, "Evaluation of requirements for Volt/Var control and optimization function in distribution management systems," Energy Conference and Exhibition (ENERGYCON), 2012 IEEE International, pp.331-336, Florence, 9-12 Sept. 2012.

[3] F. Adinolfi, F.Baccino, M. Marinelli, S. Massucco, and F. Silvestro, "Model of a real medium voltage distribution network for analysis of distributed generation penetration in a SmartGrid scenario," Innovative Smart Grid Technologies (ISGT Europe), 2012 3rd IEEE PES International Conference and Exhibition on, pp.1-7, Berlin, 14-17 Oct. 2012.

[4] L. Carradore, and R. Turri, "Electric Vehicles participation in distribution network voltage regulation," Universities Power Engineering Conference (UPEC), 2010 45th International, pp.1-6, Cardiff, 31 Aug. - 3 Sept. 2010.

[5] B. Meersman, B. Renders, L. Degroote, T. Vandoorn, and L. Vandevelde, "Three-phase inverter-connected DG-units and voltage unbalance," Electric Power Systems Research, Volume 81, Issue 4, April 2011, Pages 899-906.

[6] R. Caldon, M. Coppo, R. Turri, "Coordinated Voltage Control in MV and LV Distribution Networks with Inverter-Interfaced Users," in: Proc. IEEE Powertech 2013, Grenoble, 16 -20 June 2013

[7] R. Caldon, M. Coppo, R. Turri, "Distributed voltage control strategy for LV networks with inverter-interfaced generators," Electric Power Systems Research, Volume 107, February 2014, Pages 85-92, ISSN: 0378-7796, doi: 10.1016/j.epsr.2013.09.009, 2014

[8] W. Sinsukthavorn, E. Ortjohann, A. Mohd, N. Hamsic and D. Morton, "Control Strategy for Three-/Four-Wire-Inverter-Based Distributed Generation," IEEE Transactions on Industrial Electronics, vol. 59, no.10, pp. 3890-3899, Oct. 2012.

[9] FITformer ${ }^{\circledR}$ REG. Technical Brochure. [Online] www.siemens.com/energy/transformers

[10] W. Willems, T.L. Vandoorn, J.D.M. De Kooning, L. Vandevelde, "Development of a smart transformer to control the power exchange of a microgrid," Innovative Smart Grid Technologies Europe (ISGT EUROPE), 2013 4th IEEE/PES, pp.1-5, Copenhagen, 6-9 Oct. 2013.

[11] CIGRÉ Task Force C6.04.02, "Benchmark Systems for Network Integration of Renewable and Distributed Energy Resources", CIGRÉ report, 2009.

[12] K. Sunderland, M. Coppo, M.F. Conlon and R. Turri, "Application of a correction current injection power flow algorithm to an unbalanced 4wire distribution network incorporating TN-C-S earthing," in Proc. $48^{\text {th }}$ Universities' Power Engineering Conference (UPEC 2013), pp. 1-6, Dublin, 2-5 Sept. 2013.

[13] OpenDSS website: ww.electricdss.sourceforge.net

[14] G. Andersson, Modelling and Analysis of Electric Power Systems, ITET ETH Zurich, March 2003.

[15] X. Han, S. You, F. Thordarson, D.V. Tackie, S.M. Ostberg, O. Pedersen, H.W. Bindner, and N.C. Nordentoft, "Real-time measurements and their effects on state estimation of distribution power system," Innovative Smart Grid Technologies Europe (ISGT EUROPE), $20134^{\text {th }}$ IEEE/PES, pp.1-5, Copenhagen, 6-9 Oct. 2013

[16] P. Pillay e M. Manyage, "Definitions of voltage unbalance", IEEE Power Engineering Review, pp. 50-51, May 2001. 